\title{
Volumetric Modulated Arc Therapy for Advanced Pancreatic Cancer
}

\author{
Wietse Eppinga, Frank Lagerwaard, Wilko Verbakel, Ben Slotman, Suresh Senan
}

\begin{abstract}
Background: Intensity-modulated radiotherapy (IMRT) allows for improved sparing of organs at risk (OARs) in advanced pancreatic cancer. A planning study evaluated if volumetric modulated arc therapy (RapidArc ${ }^{T M}[R A]$ ) could be used as an alternative to IMRT in such cases.

Patients and Methods: In ten patients, five-field IMRT (5f-IMRT) plans with fixed gantry positions were compared to RA plans using similar constraints for planning target volume (PTV) and OARs. PTV coverage, conformity indices (CI), and OAR doses were compared. One patient was treated using RA and calculated dose distributions were measured in coronal planes in a solid-water phantom.

Results: RA plans showed superior mean CI of $1.09 \pm 0.02$ ( \pm 1 SD [standard deviation]) versus $1.20 \pm 0.10$ in $5 f$-IMRT $(p=0.003)$. Both techniques achieved similar sparing of the right kidney, but RA significantly reduced left kidney doses with $\mathrm{V}_{15}$ of $7.2 \% \pm 5.3 \%$ and $15.9 \% \pm 11.1 \%$, respectively; $\mathrm{p}=0.02$. RA modestly decreased mean doses to liver (13.8 vs. $15.1 \mathrm{~Gy}$; $\mathrm{p}=0.003)$, stomach (16.7 vs. $17.9 \mathrm{~Gy} ; \mathrm{p}=0.017)$, small bowel (19.8 vs. $22.1 \mathrm{~Gy} ; \mathrm{p}<0.001)$, and duodenum (38.8 vs. $41.9 \mathrm{~Gy}$; $\mathrm{p}=0.004)$. Film dosimetry revealed excellent agreement between calculated and measured dose distributions. The delivery time for RA was $<3$ min.

Conclusion: RA planning achieved superior CI for pancreatic tumors compared to 5f-IMRT, and modestly reduced OAR doses. Fast treatment delivery using RA may decrease the risk of intrafractional organ motion.
\end{abstract}

Key Words: Pancreatic cancer · Volumetric modulated arc therapy · Intensity-modulated radiotherapy · Planning study · Organs at risk

Strahlenther Onkol 2010;186:382-7

DOI 10.1007/s00066-010-2094-5

\begin{abstract}
„Volumetric modulated arc therapy“ bei lokal fortgeschrittenem Pankreaskarzinom
Hintergrund: Durch intensitätsmodulierte Radiotherapie (IMRT) ergibt sich die Möglichkeit einer niedrigeren Dosisverteilung hinsichtlich der Risikoorgane (OAR) bei Patienten mit lokal fortgeschrittenem Pankreaskarzinom. Die vorliegende Planungsstudie soll die Frage beantworten, ob "volumetric modulated arc therapy" (RapidArc ${ }^{\mathrm{TM}}$ [RA]) eine Alternative zur IMRT sein könnte.

Patienten und Methodik: Bei zehn Patienten wurden Fünf-Felder-IMRT-Pläne mit fester Gantryposition und RA-Plänen bei nahezu identischen Beschränkungen bezüglich Planungszielvolumen (PTV) und OAR verglichen. Analysiert und verglichen wurden Abdeckung des PTV, Konformitätsindizes (CI) und OAR-Dosen. Ein Patient wurde mittels RA-Technik behandelt. Dosiskalkulationen erfolgten anhand im Wasserphantom gemessener koronaler Dosisverteilungen.

Ergebnisse: RA-Pläne zeigten einen günstigeren CI von 1,09 \pm 0,02 ( \pm 1 SD [Standardabweichung]) gegenüber 1,20 \pm 0,10 bei 5f-IMRT $(p=0,003)$. Mit beiden Techniken gelang eine zufriedenstellende Dosisreduktion der rechten Niere, mittels RA konnten jedoch die $\mathrm{V}_{15}$ der linken Niere signifikant reduziert werden $(7,2 \% \pm 5,3 \%$ vs. $15,9 \% \pm 11,1 \%$ bei IMRT; $p=0,02)$. Geringer zeigte sich die Reduktion der mittleren Dosis der Leber (13,8 vs. 15,1 Gy; $p=0,003)$, des Magens (16,7 vs. 17,9 Gy; $p=0,017)$, des Dünndarms (19,8 vs. 22,1 Gy; $p<0,001)$ und des Duodenums (38,8 vs. 41,9 Gy; $p=0,004)$. Filmdosimetrische Überprüfungen zeigten hervorragende Übereinstimmungen bezüglich kalkulierter und tatsächlicher Dosisverteilung. Die Gesamtbestrahlungszeit betrug $<3$ min.

Schlussfolgerung: Mittels RA-Planung lässt sich im Vergleich zur 5f-IMRT sowohl ein günstigerer CI als auch moderate Dosisreduktion in den OAR erreichen. Durch die rasche Dosisapplikation vermindert sich das Risiko intrafraktionärer Bewegung der OAR.
\end{abstract}

Schlüsselwörter: Pankreaskarzinom • „Volumetric modulated arc therapy“ · Intensitätsmodulierte Radiotherapie • Planungsstudie $\cdot$ Risikoorgane

${ }^{1}$ Department of Radiation Oncology, VU University Medical Center, Amsterdam, The Netherlands.

Received: October 7, 2009; accepted: February 24, 2010

Published Online: June 24, 2010 


\section{Introduction}

In locally advanced pancreatic cancer, primary chemoradiotherapy appears to be superior to best supportive care and high-dose radiotherapy alone [14]. In selected patients, neoadjuvant treatment can result in downstaging of pancreatic tumors and nodal spread [32] and adjuvant chemoradiotherapy should be considered after irradical resections [20]. However, previous randomized studies have reported significantly higher rates of hematologic and gastrointestinal toxicity with chemoradiotherapy $[8,10,27]$. Late toxicity after chemoradiotherapy to the upper abdomen includes bowel strictures [16, 27] and radiation-induced nephropathy, which may manifest months to years post-treatment $[7,15]$. Measures to reduce toxicity include omitting prophylactic radiotherapy of regional lymph nodes [27], decreasing mobility margins by individualized assessment and incorporation of target mobility [33], and the use of more conformal radiotherapy techniques. In particular, use of intensity-modulated radiotherapy (IMRT) is associated with lower renal and bowel doses compared to conventional planning [2, 4, 23, 24, 31, 34, 37].

RapidArc $^{\mathrm{TM}}$ (RA; Varian Medical Systems, Palo Alto, CA, USA) is a volumetric modulated arc technique which allows for rapid planning and delivery of highly conformal intensity-modulated dose distributions using one or two $358^{\circ}$ rotations of the gantry of the linear accelerator. The planning algorithm uses progressive sampling optimization by simultaneously changing the shape of the treatment aperture, dose rate, and rotation speed of the gantry [28]. The use of RA has been previously reported for patients with tumors of the head and neck [35], multiple brain metastases [22], lung cancer [36], benign intracranial tumors [21], and prostate cancer [19,29].

In this study, we compared RA planning with conventional five-field IMRT (5f-IMRT) in ten patients who had undergone chemoradiotherapy for tumors of the pancreas. The ability of RA and conventional IMRT to reduce doses to the kidneys, the liver, and the small bowel was evaluated.

\section{Patients and Methods}

A retrospective planning study was performed in ten consecutive patients who had undergone concurrent gemcitabine-based chemoradiotherapy for locally advanced pancreatic carcinoma at our center. The same patients were the subject of an earlier comparison between three-dimensional conformal radiotherapy and IMRT [34]. Details on target definition and radiotherapy planning scans have been described previously [34]. Briefly, clinical target volumes (CTV), consisting of the pancreatic tumor and enlarged regional lymph nodes, were contoured on all phases of a planning four-dimensional computed tomography (4DCT) scan that was generated during quiet respiration. The interval between the $\mathrm{CT}$ phase bins was $1 / 10$ of the average breathing cycle time, and the axial slice thickness and reconstruction index was $2.5 \mathrm{~mm}$. During 4DCT acquisition, no oral or intravenous contrast was administered, because a recently acquired diagnostic contrast-enhanced CT or magnetic resonance imaging scan was available for all patients. Nonenlarged regional lymph nodes were not included in the CTV as is consistent with our institutional policy for chemoradiotherapy of irresectable pancreatic cancer. The internal target volume (ITV) was represented by the encompassing volume of all CTVs. The planning target volume (PTV) was derived from the addition of a margin of $1 \mathrm{~cm}$ to the ITV in order to correct for variations in respiratory-driven tumor motion and patient setup errors. Organs at risk (OARs) were contoured on all phases of the 4DCT scan, i.e., both kidneys, the liver, and the stomach. A "small-bowel region" was defined which consisted of the abdominal content after subtracting the PTV, all OARs and the vertebral bodies, with the posterior border extending to the dorsum of the lumbar vertebral body, but excluding the retroperitoneal space [30]. Our definition of a "small-bowel region" also included the mesentery and intraperitoneal fat, which is in contrast with prior reports describing bowel dose-volume relationships using bowel loop contouring [23, 24].

In contrast to the four-field IMRT (4f-IMRT) technique described previously [34], we applied an improved five-field sliding-window IMRT plan (5f-IMRT) for the ten patients, and compared this with RA plans for a total dose of $50.4 \mathrm{~Gy}$ in 1.8-Gy fractions, in accordance with the recommendations of the International Commission on Radiation Units and Measurements report 50. An earlier planning study had revealed that, for a number of these patients, the present 5f-IMRT plans allowed for reduced doses to OARs in comparison to the 4f-IMRT described previously [34] (data not shown).

Planning was primarily optimized for PTV coverage and for limiting each kidney volume receiving $\geq 15 \mathrm{~Gy}\left(\mathrm{~V}_{15}\right)$. IMRT planning was performed using the Eclipse planning system (Varian Medical Systems). Coplanar, five-field beam configurations with fixed gantry positions at $30^{\circ}, 100^{\circ}, 180^{\circ}$, $260^{\circ}$, and $330^{\circ}$ were used with 6-MV photons. A renal tolerance dose of $15 \mathrm{~Gy}$ ( $5 \%$ risk at 5 years) and $20 \mathrm{~Gy}(50 \%$ risk at 5 years) was assumed [7]. The hepatic tolerance dose (5\% risk at 5 years) was set at 30 Gy for the whole organ [11]. For the spinal cord, a maximal dose objective of 45 Gy was accepted. The maximal dose objective for the stomach was $45 \mathrm{~Gy}$ for the entire organ. Doses to the small bowel were not considered in the optimization.

RA planning was performed using two simultaneously optimized volumetric arcs (RapidArc version 8.6.3, Varian Medical Systems) as described previously [35]. The first counterclockwise arc used a $45^{\circ}$ collimator rotation, and a second arc rotated clockwise with a $40^{\circ}$ collimator rotation. No couch rotations or avoidance sectors were used. Similar constraint sets were used for both RA and 5f-IMRT plans.

Dose-volume histograms were analyzed with respect to PTV coverage, conformity indices (CI; the ratio between the volume covered by $95 \%$ of prescription dose and the PTV), and number of monitor units (MU) needed to deliver the dose. The $\mathrm{V}_{15}, \mathrm{~V}_{20}$, and mean dose of both kidneys were computed 
and compared. Both the mean dose and $\mathrm{V}_{30}$ were computed for the other OARs. Comparisons were performed using paired t-tests in SPSS v.15.0, and significance was assumed when $\mathrm{p}<0.05$.

After completion of this planning study, a patient with pancreatic cancer who underwent chemoradiotherapy was treated using RA. As is routine for all clinical RA treatments at our center, dosimetric verification of the plan was performed in a solid-water phantom on a Trilogy linear accelerator (Varian Medical Systems) prior to the start of treatment. The RA plan was measured in two coronal planes using GafChromic EBT films and compared with calculated dose distributions. Film was used as an absolute dosimeter.

\section{Results}

RA treatment plans were consistently generated within $1 \mathrm{~h}$ planning time, which consisted largely of time for calculation. 5f-IMRT plans generally took $1.5-2 \mathrm{~h}$ to complete. Tumor characteristics are listed in Table 1 . The mean volumes of the CTV and PTV were $138 \pm 67 \mathrm{~cm}^{3}$ ( \pm 1 SD [standard deviation]) and $492 \pm 189 \mathrm{~cm}^{3}$, respectively. Both IMRT and RA plans had excellent coverage of the PTV with $\geq 99 \%$ of the PTV receiving $\geq 95 \%$ of the prescribed dose. The CI obtained with RA was $1.09 \pm 0.02$, which was significantly better than that for 5f-IMRT plans $(1.20 \pm 0.10 ; \mathrm{p}=0.003)$. The mean number of MU needed to deliver the dose was significantly lower for RA (561 \pm 95 MU for RA vs. $800 \pm 209$ MU for 5f-IMRT; $p=$ $0.009)$.

RA permitted significant reductions in renal $\mathrm{V}_{20}$ (Figure 1 , Table 2). Although mean doses to both kidneys were not sig-
Table 1. Tumor characteristics. CTV: clinical target volume; PTV: planning target volume.

Tabelle 1. Tumoreigenschaften. CTV: klinisches Zielvolumen; PTV: Planungszielvolumen.

\begin{tabular}{cllcl}
\hline Patient \# & TNM & Tumor subsite & CTV $\left.\mathbf{( c m}^{3}\right)$ & PTV $\left(\mathbf{c m}^{3}\right)$ \\
\hline 1 & T4 N0 M0 & Head & 110 & 448 \\
2 & T4 N1 M1 & Body & 271 & 862 \\
3 & T4 N0 M0 & Head & 71 & 339 \\
4 & T4 N1 M0 & Head & 132 & 517 \\
5 & T4 N0 M0 & Head & 135 & 365 \\
6 & T4 N0 M1 & Head & 107 & 432 \\
7 & T4 N0 M0 & Head & 143 & 530 \\
8 & T4 N0 M0 & Tail & 52 & 280 \\
9 & T4 N0 M1 & Head & 207 & 702 \\
10 & T4 N0 M0 & Head & 208 & 674 \\
11 & T4 N0 M1 & Head & 78 & 264 \\
Mean & & & 138 & 492
\end{tabular}

nificantly different, RA plans showed a significantly lower $\mathrm{V}_{15}$ $(15.9 \%$ vs. $7.2 \%)$ and $V_{20}(6.6 \%$ vs. $2.4 \%)$ for the left kidney, and a lower $\mathrm{V}_{20}(16.8 \%$ vs. $9.9 \%)$ for the right kidney when compared to $5 \mathrm{f}$-IMRT. Both mean doses and $\mathrm{V}_{30}$ for all other studied OARs, including the liver, stomach, small bowel and duodenum, were significantly lower with RA planning than with 5f-IMRT (Table 3, Figure 2). Although in three of our patients a similar CI was found for both RA and 5f-IMRT, not a single patient would have benefitted from IMRT treatment based on dose-volume histogram comparison of all OARs.
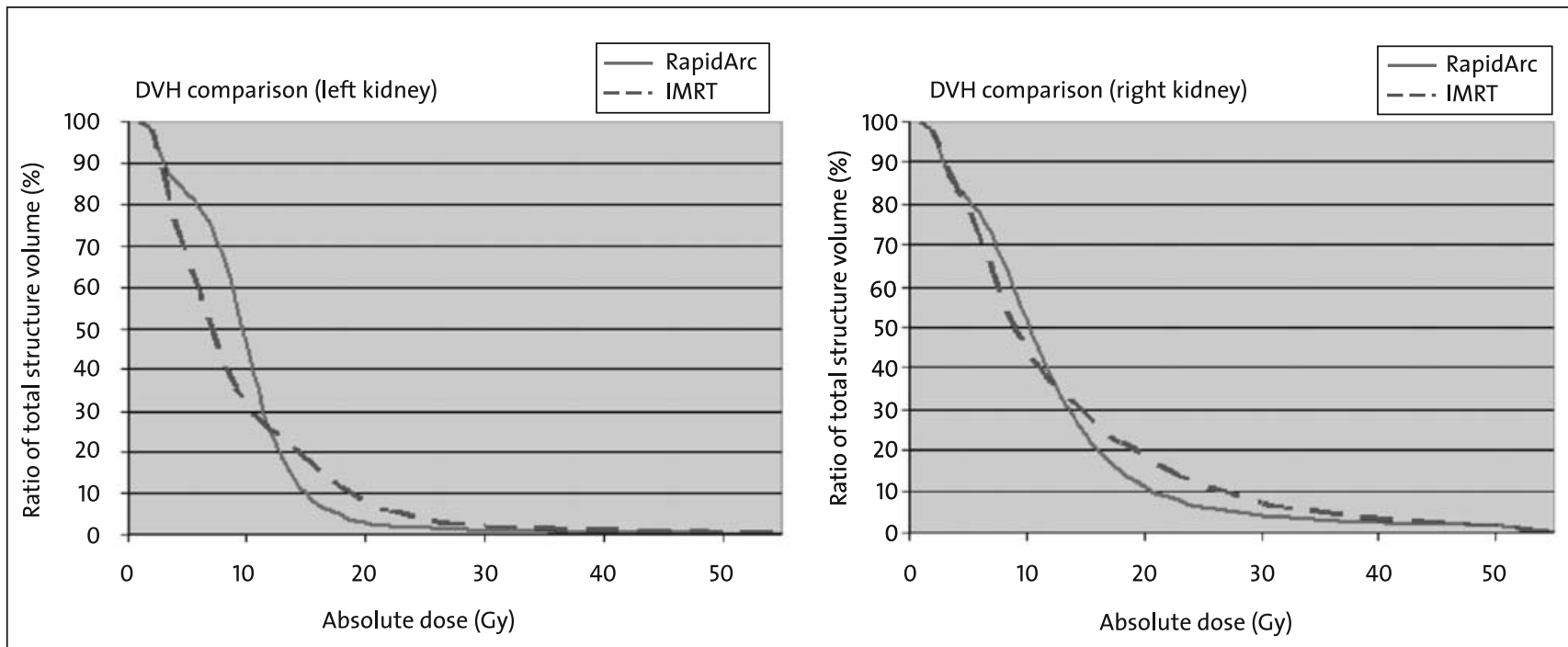

Figure 1. Average dose-volume histograms (DVH) for the right and left kidney of ten patients, achieved with RA (solid line) and $5 \mathrm{f}-\mathrm{IMRT}$ (dashed line).

Abbildung 1. Dosis-Volumen-Histogramme (DVH; kumulierter Durchschnitt) der rechten und linken Niere von zehn Patienten für RA (durchgezogene Linie) und 5f-IMRT (gestrichelte Linie). 
Table 2. Comparison of renal doses, averaged over ten patients, achieved with RapidArc ${ }^{T M}$ (RA) and five-field intensity-modulated radiotherapy (5f-IMRT).

Tabelle 2. Vergleich der durchschnittlichen Nierendosis bei zehn Patienten für RapidArc ${ }^{\text {TM }}$ (RA) und intensitätsmodulierte Radiotherapie in Fünf-Felder-Technik (5f-IMRT).

\begin{tabular}{|c|c|c|c|c|c|}
\hline & $\begin{array}{l}\text { 5f-IMRT } \\
\text { Mean }\end{array}$ & Range & $\begin{array}{l}\text { RA } \\
\text { Mean }\end{array}$ & Range & $\begin{array}{l}\text { t-test } \\
\text { (RA vs. } \\
\text { 5f-IMRT) }\end{array}$ \\
\hline \multicolumn{6}{|l|}{ Left kidney } \\
\hline Mean dose (Gy) & 8.2 & $5.1-12.4$ & 8.8 & $6.6-10.7$ & 0.369 \\
\hline $\mathrm{V}_{15}(\%)$ & 15.9 & $4.8-38.7$ & 7.2 & $0.7-16.9$ & 0.016 \\
\hline $\mathrm{V}_{20}(\%)$ & 6.6 & $1.4-12.7$ & 2.4 & $0.0-10.3$ & 0.004 \\
\hline \multicolumn{6}{|l|}{ Right kidney } \\
\hline Mean dose (Gy) & 11.6 & $5.7-25.9$ & 10.9 & $4.7-25.0$ & 0.402 \\
\hline$V_{15}(\%)$ & 26.5 & $7.5-73.6$ & 20.4 & $1.1-72.7$ & 0.132 \\
\hline $\mathrm{V}_{20}(\%)$ & 16.8 & $3.4-54.6$ & 9.9 & $0.0-49.2$ & 0.050 \\
\hline
\end{tabular}

Table 3. Comparison of doses to organs at risk, averaged over ten patients, achieved with RapidArc ${ }^{\mathrm{TM}}$ (RA) and five-field intensity-modulated radiotherapy (5f-IMRT).

Tabelle 3. Vergleich der durchschnittlichen Risikoorgandosen von zehn Patienten für RapidArc ${ }^{\mathrm{TM}}$ (RA) und intensitätsmodulierte Radiotherapie in Fünf-Felder-Technik (5f-IMRT).

\begin{tabular}{|c|c|c|c|c|c|}
\hline & $\begin{array}{l}\text { 5f-IMRT } \\
\text { Mean }\end{array}$ & Range & $\begin{array}{l}\text { RA } \\
\text { Mean }\end{array}$ & Range & $\begin{array}{l}\text { t-test } \\
\text { (RA vs. } \\
\text { 5f-IMRT) }\end{array}$ \\
\hline \multicolumn{6}{|l|}{ Liver } \\
\hline Mean dose (Gy) & 15.1 & $12.0-25.2$ & 13.8 & $9.5-22.4$ & 0.003 \\
\hline $\mathrm{V}_{30}(\%)$ & 20.9 & $15.4-45.3$ & 13.8 & $1.6-28.2$ & 0.003 \\
\hline \multicolumn{6}{|l|}{ Stomach } \\
\hline Mean dose (Gy) & 17.9 & $5.8-24.6$ & 16.7 & $7.2-24.6$ & 0.017 \\
\hline $\mathrm{V}_{30}(\%)$ & 22.8 & $0.7-38.7$ & 18.4 & $0.9-33.2$ & 0.010 \\
\hline \multicolumn{6}{|l|}{ Small bowel } \\
\hline Mean dose (Gy) & 22.1 & $18.9-26.8$ & 19.8 & $16.6-22.8$ & $<0.001$ \\
\hline $\mathrm{V}_{30}(\%)$ & 29.3 & $17.8-46.1$ & 21.0 & $12.1-27.6$ & $<0.001$ \\
\hline \multicolumn{6}{|l|}{ Duodenum } \\
\hline Mean dose (Gy) & 41.9 & $27.8-49.3$ & 38.8 & $24.7-46.8$ & 0.004 \\
\hline $\mathrm{V}_{35}(\%)$ & 75.1 & $35.2-95.6$ & 62.4 & $24.3-87.3$ & 0.004 \\
\hline
\end{tabular}

Film measurements showed that only $0.6 \%$ of the film surface receiving $>0.3$ Gy exceeded a combination of dose differences $\geq 3 \%$ and distance to agreement $\geq 2 \mathrm{~mm}$. The patient was treated using daily kilovoltage images for patient setup correction. The "beam-on" time (after the completion of patient setup) for each fraction was $<3 \mathrm{~min}$ for RA, compared to $8 \mathrm{~min}$ for 5 f-IMRT

\section{Discussion}

Several publications on pancreatic cancer have demonstrated the superiority of IMRT in reducing radiation doses to surrounding normal organs in comparison to three-dimensional conformal radiotherapy [2, 4, 23, 24, 34]. Our analysis in ten patients revealed that RA allowed for an improved CI relative
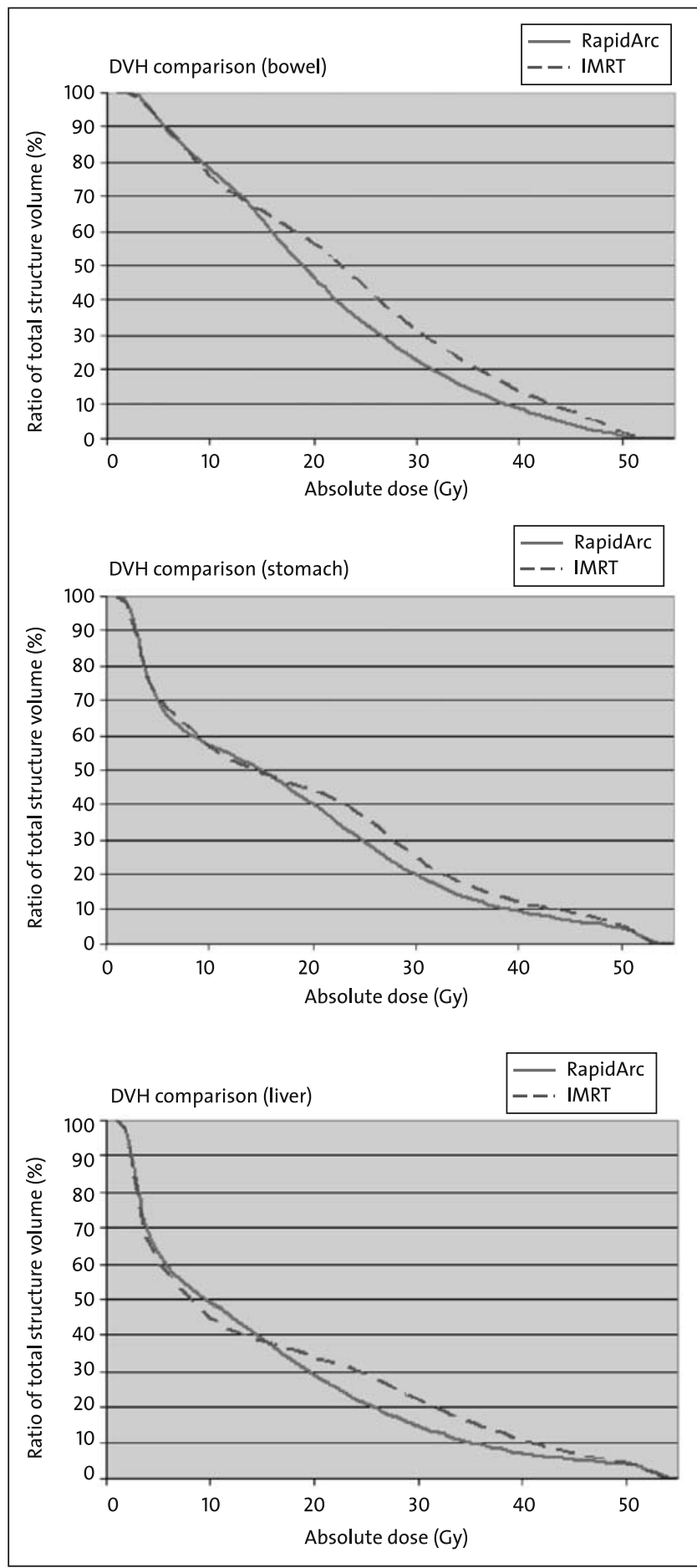

Figure 2. Average dose-volume histograms (DVH) for the bowel, liver, and stomach, achieved with RA (solid line) and 5 f-IMRT (dashed line).

Abbildung 2. Dosis-Volumen-Histogramme (DVH; kumulierter Durchschnitt) des Darms, der Leber und des Magens von zehn Patienten für RA (durchgezogene Linie) und 5f-IMRT (gestrichelte Linie). 
to a 5f-IMRT plan, and that OAR doses were also significantly reduced. RA has now been clinically implemented, with the delivery of each fraction requiring $<3 \mathrm{~min}$.

The main goal of our study was to investigate whether the increased speed in treatment planning and delivery obtained with RA would compromise the conformity and normal-organ sparing compared to conventional IMRT. A recent paper questioned the ability to generate highly modulated treatment plans using volumetric arc therapy [3]. Our study as well as recent publications in a range of tumor sites $[9,19,21,22$, $29,35,36]$ have clearly shown data to the contrary. We realize that it may be difficult to draw firm conclusions on the comparison between RA and IMRT because of differences in optimization methods, and the use of more than five IMRT fields may change the comparison.

When considering dosimetric differences between RA and IMRT, it is also important to address motion management for abdominal tumors, as craniocaudal pancreatic motion of up to $25 \mathrm{~mm}$ has been reported [6, 12]. Mean pancreatic motion on 4DCT of our patients was only $9 \mathrm{~mm}$, however, with extremes of up to $15 \mathrm{~mm}$. Inadequate margins for motion may lead to significant underdosing, in particular when highly conformal treatment techniques are used. The use of respiratory gating, breath-hold techniques or abdominal compression can lead to smaller margins and thereby smaller treatment volumes. The former approaches can substantially prolong delivery times, which can increase the risk of tumor displacement during treatment delivery, particularly as surrogate markers such as abdominal wall and diaphragm poorly correlate with tumor mobility [12]. Earlier reports suggest that respiration-gated IMRT (or carbon ion therapy) leads to only very limited dosimetric benefits for upper abdominal tumor sites [25, 33, 34]. In addition, a combination of respiratory gating with arc therapy is technically not possible in the current version of RA.

The observed dosimetric benefit of RA over 5f-IMRT was reflected in a lower CI of RA plans and significant reduction in the $\mathrm{V}_{20}$ of the right kidney. RA plans resulted in a modest, but statistically significant decrease in small-bowel and specifically duodenal doses compared to 5f-IMRT. The latter are important, as gastrointestinal complaints are the commonest acute side effects of chemoradiotherapy for pancreatic cancer [24]. The incidence of gastrointestinal toxicity correlated best with the volume of small bowel receiving doses as low as 15 Gy [1]. Our data show a superiority of RA for all doses $>15$ Gy (Figure 2).

Our protocol calls for omission of prophylactic regional node irradiation, and only enlarged nodes were encompassed in the CTV. This limitation should be kept in mind, as the sensitivity of currently available imaging methods to predict nodal involvement is poor $[17,26]$. Other groups have considered elective nodal irradiation to be appropriate due to a high likelihood of lymph node involvement in approximately $75-80 \%$ of patients who underwent surgical resection for pancreatic tumors $[5,18]$. Nevertheless, our approach results in the PTV encompassing the most common locations for nodal metastases, which are the peripancreatic and pancreaticoduodenal areas.

RA treatment delivery time was $<3$ min in our patient, and this compares favorably with 5f-IMRT delivery which takes approximately $10 \mathrm{~min}$ on a Varian linear accelerator. Besides improving patient comfort and departmental efficiency, the reduced treatment delivery will also decrease the likelihood of intrafractional changes in patient position [13].

\section{Conclusion}

RA planning for advanced pancreatic cancer results in significantly higher conformity plans than can be achieved using 5f-IMRT, which allows for increased sparing of most surrounding OARs. Based on these results and the increased speed of planning and treatment delivery, we have adopted RA as our standard treatment modality for patients with advanced pancreatic cancer.

\section{References}

1. Baglan KL, Frazier RC, Yan D, et al. The dose-volume relationship of acute small bowel toxicity from concurrent 5-FU-based chemotherapy and radiation therapy for rectal cancer. Int J Radiat Oncol Biol Phys 2002;52:176-83.

2. Ben-Josef $E$, Shields $A F$, Vaishampayan $U$, et al. Intensity-modulated radiotherapy (IMRT) and concurrent capecitabine for pancreatic cancer. Int J Radiat Oncol Biol Phys 2004;59:454-9.

3. Bortfeld T, Webb S. Single-arc IMRT. Phys Med Biol 2009;54:N9-20.

4. Brown MW, Ning $H$, Arora B, et al. A dosimetric analysis of dose escalation using two intensity-modulated radiation therapy techniques in locally advanced pancreatic carcinoma. Int J Radiat Oncol Biol Phys 2006;65: 274-83.

5. Brunner T, Merkel S, Grabenbauer G, et al. Definition of elective lymphatic target volume in ductal carcinoma of the pancreatic head based on histopathologic analysis. Int J Radiat Oncol Biol Phys 2005;62:1021-9.

6. Bussels B, Goethals L, Feron M, et al. Respiration-induced movement of the upper abdominal organs: a pitfall for the three-dimensional conformal radiation treatment of pancreatic cancer. Radiother Oncol 2003;68:69-74.

7. Cassady JR. Clinical radiation nephropathy. Int J Radiat Oncol Biol Phys 1995;31:1249-56.

8. Chauffert B, Mornex F, Bonnetain F, et al. Phase III trial comparing intensive induction chemoradiotherapy ( $60 \mathrm{~Gy}$, infusional 5-FU and intermittent cisplatin) followed by maintenance gemcitabine with gemcitabine alone for locally advanced unresectable pancreatic cancer. Definitive results of the 2000-01 FFCD/SFR0 study. Ann Oncol 2008;19:1592-9.

9. Cozzi L, Dinshaw KA, Shrivastava SK, et al. A treatment planning study comparing volumetric arc modulation with RapidArc and fixed field IMRT for cervix uteri radiotherapy. Radiother Oncol 2008;89:180-91.

10. Crane $\mathrm{CH}$, Abbruzzese JL, Evans DB, et al. Is the therapeutic index better with gemcitabine-based chemoradiation than with 5-fluorouracil-based chemoradiation in locally advanced pancreatic cancer? Int J Radiat Oncol Biol Phys 2002;52:1293-302.

11. Dawson LA, Ten Haken RK, Lawrence TS. Partial irradiation of the liver. Semin Radiat Oncol 2001;11:240-6.

12. Feng $M$, Balter $J$, Normolle $D$, et al. Characterization of pancreatic tumor motion using cine MRI: surrogates for tumor position should be used with caution. Int J Radiat Oncol Biol Phys 2009;74:884-91.

13. Hoogeman MS, Nuyttens JJ, Levendag PC, et al. Time dependence of intrafraction patient motion assessed by repeat stereoscopic imaging. Int J Radiat Oncol Biol Phys 2008;70:609-18.

14. Huguet F, Girard N, Guerche CS, et al. Chemoradiotherapy in the management of locally advanced pancreatic carcinoma: a qualitative systematic review. J Clin Oncol 2009;27:2269-77. 
15. Jansen EPM, Saunders MP, Boot $H$, et al. Prospective study on late renal toxicity following postoperative chemoradiotherapy in gastric cancer. Int J Radiat Oncol Biol Phys 2007;67:781-5.

16. Kassam Z, Lockwood G, O'Brien C, et al. Conformal radiotherapy in the adjuvant treatment of gastric cancer: review of 82 cases. Int J Radiat 0 ncol Biol Phys 2006;65:713-9.

17. Kauhanen S, Komar G, Seppänen M, et al. A prospective diagnostic accuracy study of $18 \mathrm{~F}$-fluorodeoxyglucose positron emission tomography/computed tomography, multidetector row computed tomography, and magnetic resonance imaging in primary diagnosis and staging of pancreatic cancer. Ann Surg 2009;250:957-63.

18. Kayahara M, Nagakawa T, Ohta T, et al. Analysis of paraaortic lymph node involvement in pancreatic carcinoma: a significant indication for surgery? Cancer 1999;85:583-90.

19. Kjaer-Kristoffersen F, Ohlhues L, Medin J, et al. RapidArc volumetric modulated therapy planning for prostate cancer patients. Acta Oncol 2009;48:227-32.

20. Klautke G, Brunner T. Radiotherapy in pancreatic cancer. Strahlenther Onkol 2008;184:557-64.

21. Lagerwaard FJ, Meijer OW, van der Hoorn EA, et al. Volumetric modulated arc radiotherapy for vestibular schwannomas. Int J Radiat Oncol Biol Phys 2009;74:610-5.

22. Lagerwaard FJ, van der Hoorn EA, Verbakel WF, et al. Whole-brain radiotherapy with simultaneous integrated boost to multiple brain metastases using volumetric modulated arc therapy. Int J Radiat Oncol Biol Phys 2009;75:253-9.

23. Landry JC, Yang GY, Ting JY, et al. Treatment of pancreatic cancer tumors with intensity-modulated radiation therapy (IMRT) using the volume at risk approach (VARA): employing dose-volume histogram (DVH) and normal tissue complication probability (NTCP) to evaluate small bowel toxicity. Med Dosim 2002;27:121-9.

24. Milano MT, Chmura SJ, Garofalo MC et al. Intensity-modulated radiotherapy in treatment of pancreatic and bile duct malignancies: toxicity and clinical outcome. Int J Radiat Oncol Biol Phys 2004;59:445-53.

25. Mori S, Yanagi T, Hara R, et al. Comparison of respiratory-gated and respiratory-ungated planning in scattered carbon ion beam treatment of the pancreas using four-dimensional computed tomography. Int J Radiat Oncol Biol Phys 2010;76:303-12.

26. Morimoto $H$, Ajiki T, Ueda $H$, et al. Histological features of lymph node metastasis in patients with biliary tract cancer. J Surg Oncol 2008;97:423-7.

27. Murphy JD, Adusumilli S, Griffith KA, et al. Full-dose gemcitabine and concurrent radiotherapy for unresectable pancreatic cancer. Int J Radiat Oncol Biol Phys 2007;68:801-8.
28. Otto K. Volumetric modulated arc therapy: IMRT in a single gantry arc. Med Phys 2008;35:310-7.

29. Palma D, Vollans E, James K, et al. Volumetric modulated arc therapy for delivery of prostate radiotherapy: comparison with intensity-modulated radiotherapy and three-dimensional conformal radiotherapy. Int J Radiat Oncol Biol Phys 2008;72:996-1001.

30. Roeske J, Lujan A, Rotmensch J, et al. Intensity-modulated whole pelvic radiation therapy in patients with gynaecologic malignancies. Int J Radiat Oncol Biol Phys 2000;48:1613-21.

31. Sterzing F, Schubert K, Sroka-Perez G, et al. Helical tomotherapy. Experiences of the first 150 patients in Heidelberg. Strahlenther Onkol 2008;184:8-14.

32. Tinkl D, Grabenbauer G, Golcher H, et al. Downstaging of pancreatic carcinoma after neoadjuvant chemoradiation. Strahlenther Onkol 2009;185:557-66.

33. van der Geld YG, Senan S, van Sörnsen de Koste JR, et al. A four-dimensional CT-based evaluation of techniques for gastric irradiation. Int J Radiat Oncol Biol Phys 2007;69:903-9.

34. van der Geld YG, van Triest B, Verbakel WF, et al. Evaluation of four-dimensional computed tomography-based intensity-modulated and respiratory-gated radiotherapy techniques for pancreatic carcinoma. Int J Radiat Oncol Biol Phys 2008;72:1215-20.

35. Verbakel WF, Cuijpers JP, Hoffmans D, et al. Volumetric intensity-modulated arc therapy vs. conventional IMRT in head-and-neck cancer: a comparative planning and dosimetric study. Int J Radiat Oncol Biol Phys 2009;74: 252-9.

36. Verbakel WF, Senan S, Cuijpers JP, et al. Rapid delivery of stereotactic radiotherapy for peripheral lung tumors using volumetric intensity-modulated arcs. Radiother Oncol 2009;93:122-4.

37. Wiezorek T, Schwahofer A, Schubert K. The influence of different IMRT techniques on the peripheral dose. A comparison between sMLM-IMRT and helical tomotherapy. Strahlenther Onkol 2009;185:696-702.

\author{
Address for Correspondence \\ Frank J. Lagerwaard, MD PhD \\ Department of Radiation Oncology \\ VU University Medical Center \\ de Boelelaan 1117 \\ 1081 HV Amsterdam \\ The Netherlands \\ Phone $(+31 / 20)$ 4440-414, Fax -410 \\ e-mail: fj.lagerwaard@vumc.nl
}

